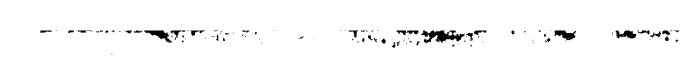

\title{
DRINK AND ITS CONTROL IN RELATION TO WORK AND HEALTH IN GREAT BRITAIN.'
}

By SIR ROBERT ARMSTRONG-JONES, M. D., MAJOR R. A. M.C.

The third report of the Central Control Board (Liquor Traffic), of which Lord D'Abernon is the chairman and Mr. J. C. G. Sykes the secretary, has just been published and it is one of the most important public documents issued during the war, for it deals with the vital subject of the health and the social life of the great masses of our population, which, in so far as its consumption of drink is concerned, is now under the control of this board, and the range of the board's actions covers in point of time not only the working period of the life of the people, but also indirectly those of its infancy and senility. The report has therefore a mental as well as an economic value. It bears upon the potentiality for "output of work" among the people and it may correctly be described as a report of the greatest social, industrial and economic moment and significance.

The board was instituted by act of Parliament in June, 1915, and it issued its first report during that year. The second, in 1916, contained a full account of the board's proceedings up to March of that year and the present, which is the third, indicates developments on the same lines and covers work applying to almost the whole of Great Britain. There is nothing in this report that touches Ireland, because any action on the part of the board must be preceded by a request to act from the military authorities, and up to the present so far as Ireland is concerned, applications to the board have only been made by social and religious bodies.

The duty of the board, as is well known, is to control the sale and supply of intoxicating excisable liquor in naval, military, munition and transport areas, and, practically stated, the functions of the board consist in maintaining the efficiency of the workers, which they have carried out mainly by extending the system of

\footnotetext{
${ }^{1}$ Defence of the Realm (Liquor Control) Regulations, 1915, Third Report of the Central Control Board (Liquor Traffic). Published by His Majesty's Stationery Office, London, 1917. Price, 3d. net. 
direct ownership and control of licensed premises and encouraging industrial canteens among the work-people, so as to replace the casual and inefficient " licensed victualling" of the ordinary public house, where drinking rather than eating was encouraged and where drunkenness rather than refreshment or restoration was the consequence.

The usual method of procedure adopted by the board in regard to any particular area is to receive a request from one of the War Departments that the regulations of the board might apply to it. Following upon this an enquiry is conducted by the board by means of local conferences and if sufficient reasons are found for action, the Minister of Munitions is advised to apply to the Privy Council for an order to "schedule" the district delimited.

During the first twelve months of the work of the board, no less than 30 districts had been so dealt with; the whole of Wales and the county of Monmouth being the thirtieth district to be scheduled. The whole of the area under the regulations of the board then contained a population of approximately 33,000,000. Since the first year 12 more districts, with 5,000,000 more people have been brought under the same regulations and only areas comprising a total population of about $3,000,000$ now remain under the old liquor conditions and it is somewhat anomalous that $19 / 20$ of the total population of Great Britain should be under the regulations of the Defence of the Realm Act and covered by the authority of the Board of Control (Liquor Traffic) whilst $I / 20$ is immune from this control.

The functions of the board are not only connected with diminishing accessibility to strong drink by reducing the hours during which its sale is permitted, but the board have power and they have used it to legalize the sale of spirits and beer of lower strength than formerly; the board now permits spirits to be diluted to 35 per cent under proof, or in the case of gin to 50 per cent under proof, and in the case of beer to that containing 2 per cent of alcohol, this beer being permitted to be sold in any licensed house or club during all hours of the day from 9 a. m. until the local closing time. For the information of the purchaser the amount of alcohol contained in medicated wines must now be clearly stated on the label placed upon the bottle. The board has used its power to close all premises not hotels, refreshment rooms or restaurants 
during the hours that are not for the sale of liquor, and it has entirely prohibited Sunday opening in districts contiguous to those (Wales and Scotland) in which it was already the law to observe Sunday closing. It has entirely suspended the sale of spirits in some districts and its evening sale in others. The board also has its own inspectors and supervisors in some special areas, so that not only the quality of the liquor, but also the opportunities for its use and the conditions under which it is consumed are under the direct control of the board, and it is justifiable, after such an experience, to draw conclusions from its work. Two years and a half have now elapsed since the board commenced its work and the results have exceeded the most sanguine expectations. It was not anticipated by the most earnest social reformer-probably least of all by him-that a newly appointed committee with no previous record, working on new experimental lines and this without specific statutory instructions should have successfully completed so great a task and effected so great a change in the social life of the nation. If the aid of Parliament had been invoked through a definite campaign to limit the sale of drink to four or four and a half hours a day it would without doubt have been doomed to failure, yet the Board of Control has accomplished this task. The turmoil and the emotional excitement of war time do not tend to mental or moral inhibition nor to sobriety and orderliness of conduct. The withdrawal of the head of the house from the direction and control of family life, the enlistment of so many school teachers, the darkening of the streets in the evenings and the tendency during crises for men and women to confer together and the apparent great increase of financial prosperity due to the colossal national borrowing have all of them been conditions favorable in our belief to increased drinking, especially to the two kinds of drinking that lead to various excesses, viz., industrial and convivial. Both these forms of taking strong drink have a tendency to increase during periods of artificial stimulation, yet throughout the whole of this time there has in fact been a heavy reduction of convictions for drunkenness among women as well as men in all the areas that have been scheduled by the board. The reduction commenced with the action taken by the board and it has continued steadfastly ever since the change in the liquor control was initiated. 
It is well shown diagrammatically in the charts submitted by the board that in I9I4 the total number of convictions in greater London and in the cities and boroughs of Great Britain with a population of over a hundred thousand was approximately 156,000 but in 1916 this was reduced to 77,000 , the corresponding figures for women being 41,000 and 24,000 respectively. The hours during which licensed houses under the board are open are the two hours for the two chief meals in the day, viz., two hours from noon during the mid-day dinner and two hours in the evening during supper. Some authorities attribute improvement to the early evening closing, but it is eminently satisfactory that the improvement continues. It is maintained by some adverse critics that convictions for drunkenness relate mainly to drunkards, but since the board's regulations have been in force in scheduled areas there has been much better time-keeping among the workmen with a consequent increase in the "output of work," also the drinking described as "soaking" with disgraceful street scenes and hurtful examples to the morals and conduct of the young have been made difficult and in many instances impossible ; further there has been a greater control over convivial drinking through the stopping of " treating " and through the prohibition of credit for drinks. It has also been asserted by adverse critics that the regulations of the board have caused a diversion of drinking from the licensed house to the home and that "home drinking" has increased in consequence. The opinion of social workers, of health visitors and members of the police is directly opposed to this view and statistics of deaths from delirium tremens and from alcoholism-which would be the inevitable sequence of home drinking-do not support these views of the adverse critics. On the contrary, there is a diminution in both alcoholism and the records of delirium as there is in the statistics for drunkenness. In the work of assisting to carry out their regulations the board give full credit to the efforts of the police who have worked these new rules without friction, an acknowledgment which is supported also by delegates both from employers and employed, from labor organizations and even from representatives of the licensed trade itself as well as from those in naval, military and official civil life. It is not generally known that the board have the power to close licensed houses when on a report from the chief constable it is considered to be prejudicial 
to the proper control of the liquor traffic for these premises to remain open and 85 such premises have been closed in Great Britain for the remainder of the licensing year.

The great work in favor of temperance which the Board of Control have effected has been done on rational lines and entirely because workers in munition and transport areas had to be provided with appropriate and satisfactory feeding places. It was delegated to this board to arrange, and if necessary, to provide, facilities for obtaining for workers wholesome and sufficient nourishment and it was recognized that this could only be done by vigorous action in supplying suitable nutrition and in controlling the sale of drink; both these aspects were closely related to the health of the worker and in consequence to his energy and output for work. To keep the worker physically fit and at full capacity of working power, to prevent fatigue, exhaustion or the onset of disease were the one aim of the board and by increasing the facilities for obtaining suitable meals at public houses and licensed restaurants and by establishing industrial canteens which could supply substantial meals and light refreshment at reasonable prices the board effected this desired end. The canteen system was run at first by voluntary effort through public subscriptions, supplemented as may have been necessary by a treasury grant-inaid of one-half the capital expenditure, but the employers after a time took the place of the languishing voluntary subscriptions and later the system came to be supported by the "extra-profits" of the employers and payments were made out of revenue which would otherwise accrue to the exchequer. In government establishments the state acted as the employer and undertook the expense, leaving the board to be the responsible organizing authority, so that for the last 18 months the industrial canteens of the whole country have been under the organization and control of the board, and up to the end of March this year there were 570 canteens providing suitable nutritive material for nearly $2,000,000$ of workers and in which the workers could find easily digestible, appetizing and attractive food served to them at a reasonable cost, and the extent of this system may be gathered by the fact that three-quarters of a million of money was provided out of the profit of controlled establishments apart from $t_{12}, 000$ made as grantin-aid to voluntary societies and another grant made from govern- 
ment funds to the national factories. As to the liquor side of the canteens with the exception of a few registered as clubs supplying one pint of light beer with a meal, they are all "dry" canteens, no intoxicants being sold.

It is difficult to overestimate the comfort accorded to workers by the establishment of industrial canteens and the gain to health is still more. The work of the board in making life contented and human in isolated factories, the fuller output of work, and the better time-keeping; the reduction of temptation to drink through the supplying of better food and the general tendency towards sobriety are some of the incidents which demonstrate a vital change in the industrial life of the nation and the board may be said to have solved the problem of the employment of men and women together and to have proved one of the most valuable "welfare" factors in the life of the industrial classes. It has not only served as a most useful civilizing influence among employés, but it has shown an example which large employers of labor cannot fail to emulate, for the industrial canteen has won its place as a permanent and essential feature of the modern factory.

This report of the board which we have now reviewed concludes with an almost romantic account of the control exercised by it over the sale of liquor in the city of Carlisle and in the district of Gretna, surrounding the Gretna National Explosives Factory. As is well known the men employed at Gretna were housed in Carlisle, and these men, together with those living in huts at Gretna, resorted in crowds to Carlisle on Saturdays. This implied that the male population of a quiet cathedral city was more than doubled by the incursion of highly paid workmen without special interests or family ties and soon the convictions for drunkenness rose from 5 per week to 42 per week, so that the board in a bold stroke decided after consultation with the local authorities to purchase practically the whole of the 200 licensed premises together with the working undertakings of the five breweries and the complete business of the wine and spirit merchants. Two of the breweries are closed and over 70 of the licensed premises, in addition the sale of spirits on Saturdays has been prohibited. Two taverns have been opened upon a new model so that the sale of intoxicating liquor in the shape of light beer could be carried on together with the sale of food, and the latter constitutes 75 per 
cent of the total takings. Large halls are provided together with reading and billiard rooms, and in five selected centers of the city a complete reconstruction of the public houses is taking place: the small rooms and quiet "snugs" difficult of supervision and observation are being practically abolished. The licensed houses are all inspected and each manager is impressed with the fact that he is to have no pecuniary interest in the sale of intoxicating liquor; that his fitness is judged by the standard of sobriety and good order maintained in his house rather than by profits upon the sale of intoxicants; for his personal profits and salary are only to accrue from the sale of food. Spirits are not to be sold to persons under the age of 18 and beer only if taken with meals. Another feature of the administration is the reduction in "offconsumption" licenses, which have been reduced from 100 to 17 and a close watch is kept upon this side of the business. All joint sales of groceries and intoxicants have been brought to an end and the net result has been a marked diminution in convictions for drunkenness, the condition of the streets has become eminently satisfactory and the most encouraging reports are received on every hand as to good order and improved public behavior. The work of the Board of Control has not been carried out upon any previously known plan or type and the districts of Carlisle and Gretna have not been easy localities for experiments owing to their division into English and Scotch national boundaries each with differences of law and custom such as prevail in the two countries. At Gretna the board erected a spacious one-storied building in the center of the town and provided accommodation for the service of food and non-intoxicants, for the convenience of 200 persons. They artistically and tastefully decorated the interior and provided an outside verandah and a bowling-green and added a cinema house to serve as a place of public entertainment. The sale of liquor in grocery establishments was discontinued and one-third of the "on" license houses has been closed. Police statistics support the fact that there has been a marked diminution in the convictions for drunkenness and that public sobriety has received considerable encouragement; there has been an improvement in the condition of the streets and better behavior on the station platform. The board has the satisfactory record of an increase in the sales of food and non-intoxicants at some of these canteens 
at the rate of nearly 700 per cent as compared with the increase of a little over 100 per cent in the case of intoxicating liquor; and it is proved that by extinguishing private interest in the sale of liquor and establishing control and inspection over it, it is possible to reduce to a very marked degree the excessive drinking which goes on under private management, also that when facilities are provided for recreation and for the sale of food with surroundings of decency and comfort, customers are less inclined to drink to excess. It is certain that many people frequent public houses who desire to obtain food, yet no attempt under ordinary circumstances is made to meet this demand. The experience of the Board of Control (Liquor Traffic) is emphatically in favor of a united system such as would be secured by "state management" of the licensed trade and the board deserves the whole-hearted thanks of the community for its clear, energetic and single-minded efforts to humanize labor and to perfect the laborer. These efforts have been successful beyond the most sanguine expectations and they reflect the greatest praise and credit upon the chairman, his colleagues and the indefatigable secretary. 